Article

\title{
Application of Source-Sink Landscape Influence Values to Commuter Traffic: A Case Study of Xiamen Island
}

\author{
Tong Wu ${ }^{1,2}$, Lina Tang ${ }^{1}$ (i), Huaxiang Chen ${ }^{1,2}$ (i) , Ziyan Wang ${ }^{1,2}$ and Quanyi Qiu ${ }^{1, *}$ \\ 1 Key Laboratory of Urban Environment and Health, Institute of Urban Environment, \\ Chinese Academy of Sciences, Xiamen 361021, China; twu@iue.ac.cn (T.W.); Intang@iue.ac.cn (L.T.); \\ hxchen@iue.ac.cn (H.C.); zywang@iue.ac.cn (Z.W.) \\ 2 University of Chinese Academy of Sciences, Beijing 100049, China \\ * Correspondence: qyqiu@iue.ac.cn
}

Received: 26 October 2017; Accepted: 9 December 2017; Published: 19 December 2017

\begin{abstract}
Landscape patterns are closely related to ecological processes. Different spatial scales and research methods may lead to different results. Therefore, it is crucial to choose suitable research methods when studying different landscape patterns and ecological processes. In the present study, the methods of source-sink landscape theory were applied to the interactions between urban landscape characteristics and commuter traffic behavior around the arterial roads in Xiamen Island. After classification of land use types using remote sensing images from the IKONOS satellite and ArcGIS software (ESRI, Redlands, CA, USA), the landscape patterns of areas surrounding arterial roads (within $1 \mathrm{~km}$ ) were evaluated using source-sink landscape influence (SLI). The results showed that Xiamen Island's urban expressway had the highest SLI value (0.191), followed by the state highways (0.067), the provincial highways $(0.030)$, and the county roads $(0.025)$. When considering all road types, the correlation between a road's SLI value and its commuter traffic flow was 0.684 . This result was explained by three observations: (1) The contribution of the core area of each landscape pattern to traffic flow was positively correlated with the traffic flow. (2) Areas surrounding the urban expressway and the state highways had lower values for Shannon's diversity index, indicating that these areas had a lower degree of landscape fragmentation. (3) The landscape patterns surrounding the urban expressway and the state highways were more concentrated and complex than those around other road types. The application of source-sink landscape pattern theory allows for researchers to integrate the relationships between landscape patterns surrounding roads and commuter traffic flow on those roads and to analyze the reasons for these relationships.
\end{abstract}

Keywords: urban landscape; commuter traffic flow; landscape pattern; source-sink landscape pattern; source-sink landscape influence

\section{Introduction}

"Source" and "sink" are very important concepts in the field of ecology. Pulliam proposed the source-sink model of population dynamics in 1988. Since that year, the model has become a foundation of theoretical ecological research into population dynamics and has contributed to the conservation of threatened species [1-3]. This paper is based on an application of source-sink dynamics to landscapes; this was first proposed by Chen et al. in the context of nonpoint source pollution, and is known as source-sink landscape theory [4,5]. In a source-sink landscape model, a "source" is a landscape type that promotes the development and progression of a specific ecological process, and a "sink" is a landscape type that prevents or delays the development and progression of that ecological process [4]. Some landscape types play a role in the transmission of ecological processes or influences, and are 
defined as "flow" landscapes [6]. For example, in the generation of nonpoint source pollution, some landscape types play a role as pollution "sources", some play a role as pollution "sinks", and some play a role in the transmission of pollution and are termed "flow" landscapes [7]. Because "sources" and "sinks" are defined with reference to a particular ecological process, their identities within a particular landscape should be determined only after specifying the ecological process under study.

The basic premise of landscape ecology is that landscape patterns are closely related to ecological processes [8]. However, the best method for analyzing the interaction between landscape patterns and ecological processes depends on the spatial scale [9]. Some existing literature on landscape patterns has only focused on analyzing landscape patterns, while ignoring the actual meaning or impact of these patterns [5]. The interactions between landscape patterns and ecological processes are restricted by spatial scale. The interaction between a particular landscape pattern and a particular ecological process should be analyzed in detail based on conclusive evidence [10]. It can be difficult to choose a suitable index in a particular analysis because there are many indices that are available for landscape pattern analysis. Fifty-six kinds of landscape index can be calculated in FRAGSTATS 3.3 [11]. Many studies therefore use a set of indices rather than a comprehensive index to describe landscape patterns [12]. Source-sink landscape theory is recommended as an effective method for integrative analysis of landscape patterns and ecological processes [4].

Chen et al. (2003) applied source-sink theory to nonpoint source pollution, a prominent environmental problem. By analyzing of the roles of different landscape types in the generation of nonpoint source pollution, and by using the Lorenz curve, the authors put forward a scale-independent landscape contrast index that is capable of quantitatively depicting the relationship between landscape spatial distribution patterns and ecological processes [5].

At present, source-sink landscape pattern theory is mostly applied to research on nonpoint source pollution in watersheds. For example, Sun et al. found that the source-sink landscape index could be used to measure spatial variation in total nitrogen, to provide a reference for evaluating nonpoint source pollution in watersheds, and to improve the simulation accuracy of water quality models [13]. $\mathrm{Li}$ et al. found that the Location-Weighted Landscape Index ( $L W L I)$ revealed the characteristics of soil erosion in a watershed and could be used as an effective index to evaluate soil erosion [14]. Jiang et al. used source-sink landscape pattern theory to identify the "sources" and "sinks" for nonpoint source pollutants in the area around Xiamen Island in Fujian Province, China. [15].

Studies applying source-sink landscape theory to urban areas have seldom been reported. The circulation and feedback relationship between transportation and land use is objective existence. Land is used to provide for traffic needs, to enhance and improve accessibility, and to influence the social space, stimulating new land development again and again; this generates a cycle in which land use and traffic influence each other until they eventually come into balance [16]. In China, the configurations of urban residential areas are undergoing huge changes. These changes will influence the populations, types of work, and spatial land-use distributions that are present in urban areas, as well as the resulting commute patterns of urban residents [17]. The interaction between an urban area's traffic system and its spatial land-use pattern has unique characteristics [18].

In this research study, we use the theoretical framework provided by Chen et al. in their paper on source-sink landscape theory [4] to discuss source, sink, and flow landscapes in the context of urban traffic. We believe that the framework provided by Chen et al. [4] is appropriate for this study because, at a macro scale, the behavior of urban commuter traffic is similar to the behavior of nonpoint source pollution, with traffic flowing in particular directions and gathering in particular areas. The application of source-sink landscape theory to the behavior of urban commuter traffic can allow for researchers to eliminate extraneous landscape types and focus their analysis on the relevant landscapes so that the results are targeted.

The areas surrounding arterial roads are sensitive areas that clearly reflect the effects of urbanization on urban systems [19]. When compared with other trips, daily commutes are more consistent in time and space, and their schedules affect urban residents' other activities and trips. 
Along with people work more distantly from home than previously, commuter trips have not only increased rapidly in number, but have become increasingly complicated. Commuter traffic is concentrated in peak hours and in particular areas, which gives rise to traffic jams in the morning and evening peak hours. This has become the most prominent problem in the management of urban traffic [20]. Xiamen Island is a typical urban island with definite geographical boundaries. Statistical data can accurately represent the traffic system in this island [21]. In this study, commuter traffic behavior on the arterial roads in Xiamen Island was investigated using the methods of source-sink landscape theory. We analyzed the relationship between traffic flows on different roads and landscape patterns in the areas surrounding the roads (within $1 \mathrm{~km}$ ) in order to provide support for further study on urban source-sink landscapes.

\section{Materials}

\subsection{Research Area}

Xiamen City, located in southeast Fujian Province $\left(24^{\circ} 24^{\prime} \sim 24^{\circ} 55^{\prime} \mathrm{N}\right.$ and $\left.118^{\circ} 02^{\prime} \sim 118^{\circ} 13^{\prime} \mathrm{E}\right)$, is one of the five special economic zones in China and has jurisdiction over Siming, Huli, Jimei, Haicang, Tongan, and Xiangan districts. According to the 2016 "Xiamen Special Economic Zone Yearbook", Xiamen Island, the area investigated in this study, has an area of 157.76 square kilometers under the jurisdiction of Siming and Huli districts and is the political, economic and cultural center of Xiamen City (Figure 1). By 2015, civilian vehicles registered in Xiamen City had reached 1,412,446, a threefold increase since 2005. Previous reports showed that the main road sections during peak hours in Xiamen Island were becoming crowded with traffic, with an average traffic flow of $3200 \mathrm{pcu} / \mathrm{h}$, an average saturation close to 0.7 , and an average speed of $23 \mathrm{~km} / \mathrm{h}$ at the evening peak [22]. Transportation modes in Xiamen Island are mainly divided into two types; namely, public and personal transportation. Commuter traffic includes taxis, commuter buses, conventional buses, rapid transit buses, and private cars [23].
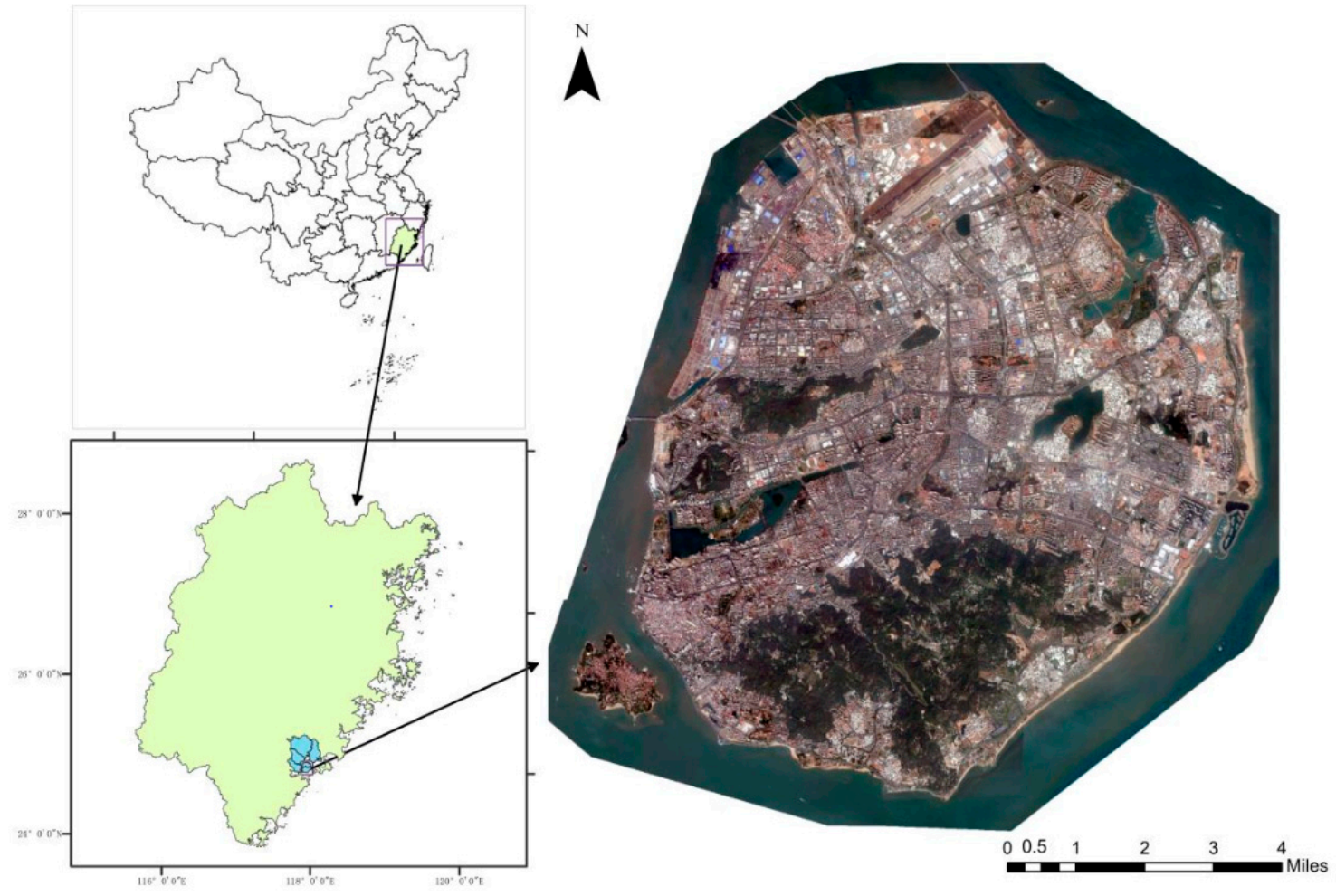

Figure 1. Location of the study area. The satellite image comes from the Google map. 


\subsection{Data Source}

Sources of data used in this study include land usage and traffic data. Land usage data were interpreted from images taken by the high-resolution imaging satellite IKONOS (2009), classified manually, and updated to 2015 by using the POI (point of interest) data of the Gaode electronic map. Traffic data included road network and traffic flow data for all roads in Xiamen Island. The road network data were integrated with the land usage data. Because we faced limitations in data gathering, the traffic flow data was simulated using the TRANUS model. This model was developed by de la Barra and Perez in 1982 [24,25] and has been applied in studies of land use and transport in Baltimore, Sacramento, Osaka, Caracas, Bangalore and other cities [26]. In order to limit our simulation to commuter travel, we obtained locations of residences and locations of workplaces, then input these as origin nodes and destination nodes, respectively, for the TRANUS model simulation. The data needed for the simulation were obtained from the questionnaire "Residential area morphological change and urban metabolic efficiency of Xiamen city", which included personal information, basic family information and travel information, such as location of work, start time of travel, travel mode, elapsed time during travel, etc. For this study, data on commutes to and from the workplace were extracted from questionnaire data [27]. The simulation time period was the morning commuting peak, from 7:00 a.m. to 9:00 a.m.

\section{Methods}

\subsection{Land Use Classification}

In order to obtain detailed land use information at the scale of Xiamen Island, this study adopted high-resolution remote sensing images of Xiamen from the IKONOS satellite as a base. The IKONOS satellite can provide panchromatic imagery at $1 \mathrm{~m}$ resolution and multispectral imagery at $4 \mathrm{~m}$ resolution. The image quality is good and the return cycle is short; this imagery is widely used in research on the urban environment [28,29]. Remote sensing image preprocessing was performed in the ENVI 4.7 software (Exelis Visual Information Solutions, Boulder, CO, USA), environment, a geometric correction for IKONOS influence was made, and projection parameters were defined. Next, the Gram-Schmidt image fusion method was used to fuse panchromatic and multispectral band IKONOS images, producing high-resolution multispectral images.

A large amount of spatial information can be contained in high-resolution remote sensing images. Together with the complexity of urban terrain types, this means that high-resolution remote sensing images can have different spectra, and the spectra of different bodies can be in common [30]. In order to prevent situations in which remote sensing classification methods, such as supervised classification and unsupervised classification, have features and spectral information that do not match, this study adopts the method of artificial visual interpretation to extract Xiamen land use information.

\subsection{TRANUS Modeling}

TUS 11.0.0 and TRANUS 11.0.0 were used to carry out the traffic simulation. TUS 11.0.0 is an interactive data processing platform for land use and traffic network database building. TRANUS 11.0.0 is integrated with many analysis models. TRANUS data processing and analysis methods are detailed in "TRANUS: Integrated Land Use and Transport Modeling System" and in the reference materials for the software [31].

\subsection{Source-Sink Landscape Theory}

\subsubsection{Source-Sink Landscape Classification}

Based on source-sink landscape theory and the specifics of the situation under study in this paper, a "source" is defined as an area from which many commuter vehicles originate, and a "sink" is defined as an area to which many commuter vehicles travel during the daily commute. Thus, a residential area 
dominated by vehicle outflow is a "source", while an area to which many workers commute is a "sink". Therefore, the vehicle flow direction generated by the landscape type is used to classify the landscape type of the source or sink. For example, an area with "residential type" land use will be dominated by vehicle outflow during the period from 7:00 a.m. to 9:00 a.m., and an area with "working type" land use will be dominated by incoming traffic during the same period. According to this standard, the land usage types that are relevant to commuter traffic in Xiamen Island were classified into source landscapes and sink landscapes. The former included urban residential lands and residential lands within urban villages. The latter included industrial and mining lands, land used by educational institutions, commercial and service areas, and construction sites. In source-sink landscape theory, the same landscape type can be considered a "source" or a "sink" depending on the ecological process under investigation, and the landscape type's role in that process [6]. In this study, mixed commercial and residential lands will produce both outflow and inflow direction; therefore, areas with this land use type act as both "sources" and "sinks" for commuter traffic, and are classified as both "source" and "sink" landscapes in the study (Figure 2). As residents tend to use the nearest commuter traffic network, this study selected 72 arterial roads in Xiamen Island, as well as a 1-km buffer zone on each side of each of these "flow" landscapes. The locations were sampled and used to analyze the relationship between traffic flow and source-sink landscape distribution.

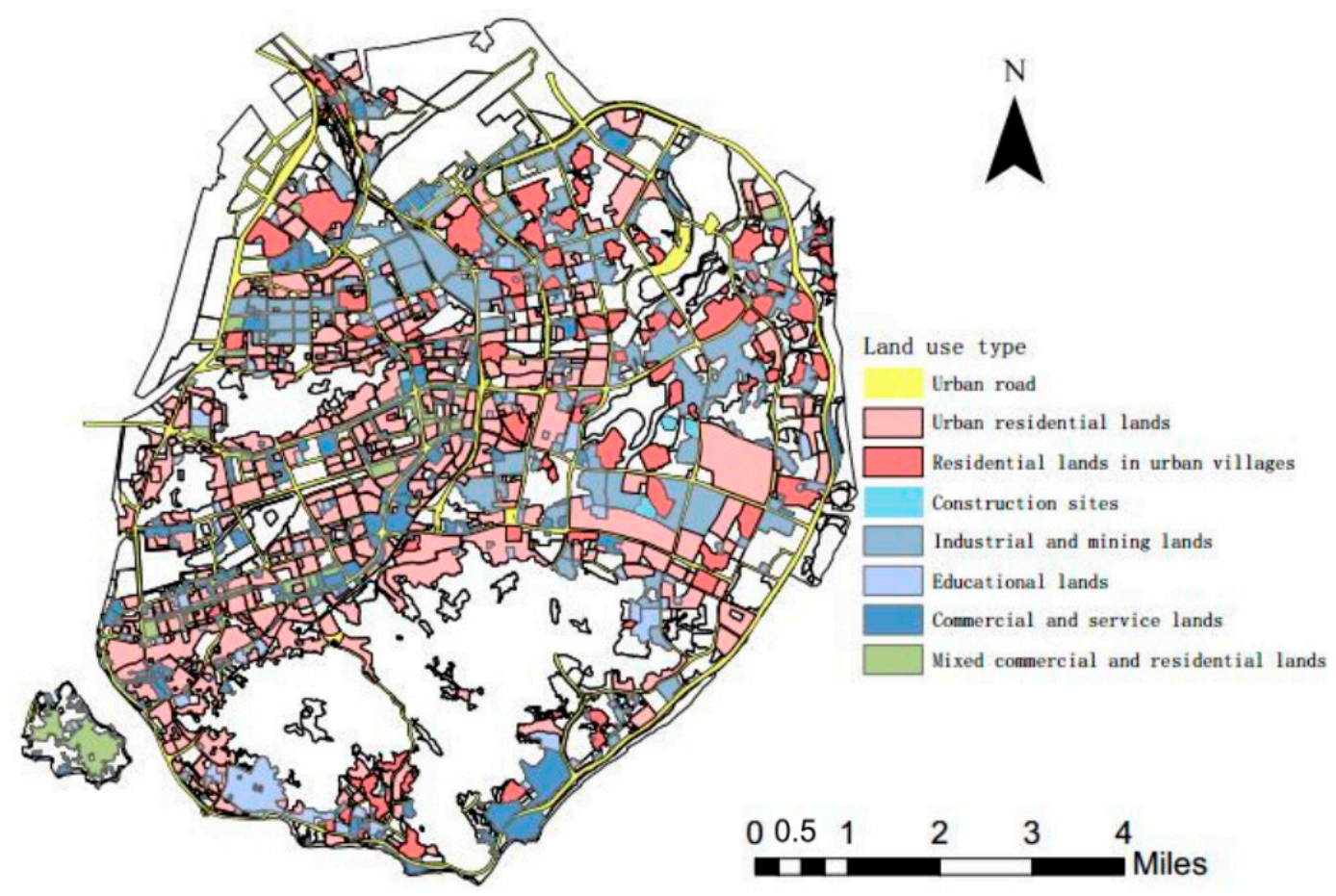

Figure 2. Source-sink landscape distribution in Xiamen Island.

\subsubsection{Source-Sink Landscape Influence}

The Location-Weighted Landscape Index (LWLI) was developed from the Lorenz curve by Chen [32]. Its theoretical assumptions and detailed derivation have been described in published literature. The $L W L I$ was calculated by proceeding through the following steps: the accumulated area accounted for by each landscape type in each 250-m buffer zone of each road was calculated by using the IKONOS interpreted vector files and ArcGIS 10.3 software (ESRI, Redlands, CA, USA). An area accumulation curve was drawn by using the relative distance and the accumulated area ratio as the horizontal and the vertical coordinates, respectively. The polygon formed by the curve, and the horizontal and the vertical coordinates, defined as $A_{\text {sourcei }}$ and $A_{\text {sinkj, }}$, were used to calculate $L W L I$ of each road using Formula (1): 


$$
L W L I=\sum_{i=1}^{m} A_{\text {sourcei }} \times W_{i} \times A P_{i} /\left[\sum_{i=1}^{m} A_{\text {sourcei }} \times W_{i} \times A P_{i}+\sum_{j=1}^{n} A_{\text {sinkj }} \times W_{j} \times A P_{j}\right]
$$

in which $A_{\text {sourcei }}$ is the area of the Lorenz curve that the $i$ th source land use type vs the relative distance. $A_{\text {sinkj }}$ is the area of the Lorenz curve that the $j$ th sink land use type vs the relative distance. Respectively, $W_{i}$ and $W_{j}$ are the weights of the $i$ th source and the jth sink land use type. $m$ is the number of source landscapes, and $\mathrm{n}$ is the number of sink landscapes. $A P_{i}$ is the area percentage of the ith source landscape, and $A P_{j}$ is the area percentage of the $j$ th sink landscape in an area.

The LWLI was originally developed for the study of nonpoint source pollutants and soil erosion. If applied to other fields, the characteristics of the relevant ecological processes should be considered to establish an appropriate evaluation model [4]. In this preliminary experiment, we found that the LWLI was not an ideal model to simulate urban commuter traffic. The results are shown in Table 1 in Section 4.2. The LWLI could not perfectly represent the relationship between source-sink landscape patterns and commuter traffic flow. To improve the application of source-sink landscape theory to urban landscape research, this study puts forward a new evaluation metric, the source-sink landscape influence (SLI) value, to substitute for the $L W L I$ in this study. The higher the SLI value, the greater influence that source-sink landscapes have on the process or flow under study in the research area. The SLI is calculated using Formula (2):

$$
S L I=\sum_{i=1}^{m} A_{\text {sourcei }} \times W_{i} \times A P_{i}+\sum_{j=1}^{n} A_{\text {sinkj }} \times W_{j} \times A P_{j}
$$

in which $A_{\text {sourcei }}$ is the area of the Lorenz curve that the $i$ th source land use type vs. the relative distance. $A_{\text {sinkj } j}$ is the area of the Lorenz curve that the $j$ th sink land use type vs the relative distance.

In order to prevent a situation in which land use area is large but the actual utilization area is small, the $W$ based on the land usage data was updated to 2015 using the POIs data of the Gaode electronic map and was used to distinguish the contribution ratios of different POIs on each road by the mean square method [33]. The detailed steps were as follows:

We performed standardization of the data to distinguish the contributions of the "source" and the "sink" landscapes. The result of Formula (3) was the positive index, and that of Formula (4) was the negative index:

$$
\begin{aligned}
& z_{i j}=\left(x_{i j}-x_{j \min }\right) /\left(x_{j \max }-x_{j \min }\right) \\
& z_{i j}=\left(x_{j \max }-x_{i j}\right) /\left(x_{j \max }-x_{j \min }\right)
\end{aligned}
$$

In these equations, the $z_{i j}$ is the standardized random variable, the $x_{i j}$ is the statistical value of the index, and the $x_{j \min }$ and the $x_{\text {jmax }}$ represent the minimum and the maximum values of the same index, respectively. The $i$ and the $j$ are the sample numbers. Based on the specific situation under study in this research, the weights were calculated with positive weights.

Calculation of the mean $\left(p_{j}\right)$ of the random variable $x_{i j}$ and of its mean square $\left(\sigma_{j}\right)$.

$$
\begin{gathered}
p_{j}=\frac{1}{n} \sum_{i=1}^{n} z_{i j} \\
\sigma_{j}=\sqrt{\sum_{i=1}^{n}\left(z_{i j}-p_{j}\right)^{2}}
\end{gathered}
$$

Calculation of the weights $\left(w_{j}\right)$ of the random variable $z_{i j}$.

$$
w_{j}=\sigma_{j} / \sum_{i=1}^{m} \sigma_{j}
$$




\section{Results}

\subsection{Values of Source-Sink Landscape Influence}

SLI was calculated based on the Lorenz curve. Spatial configurations of different landscapes, along with the variations in phase distance, were calculated by combining distance with spatial distribution of the "source" and the "sink" landscapes. With the increase in relative distance from the road to the surrounding landscape, "source" and "sink" landscapes in the area of influence are also on the rise. Using Formula (2) and the values of "source" and "sink" landscape influence, the spatial configurations of different landscape types and their changes with relative distance were calculated; the specific distribution is shown in Figure 2. The higher the SLI value, the greater the influence that the source-sink landscapes have on the traffic flow. The SLI value distribution is shown in Figure 3.

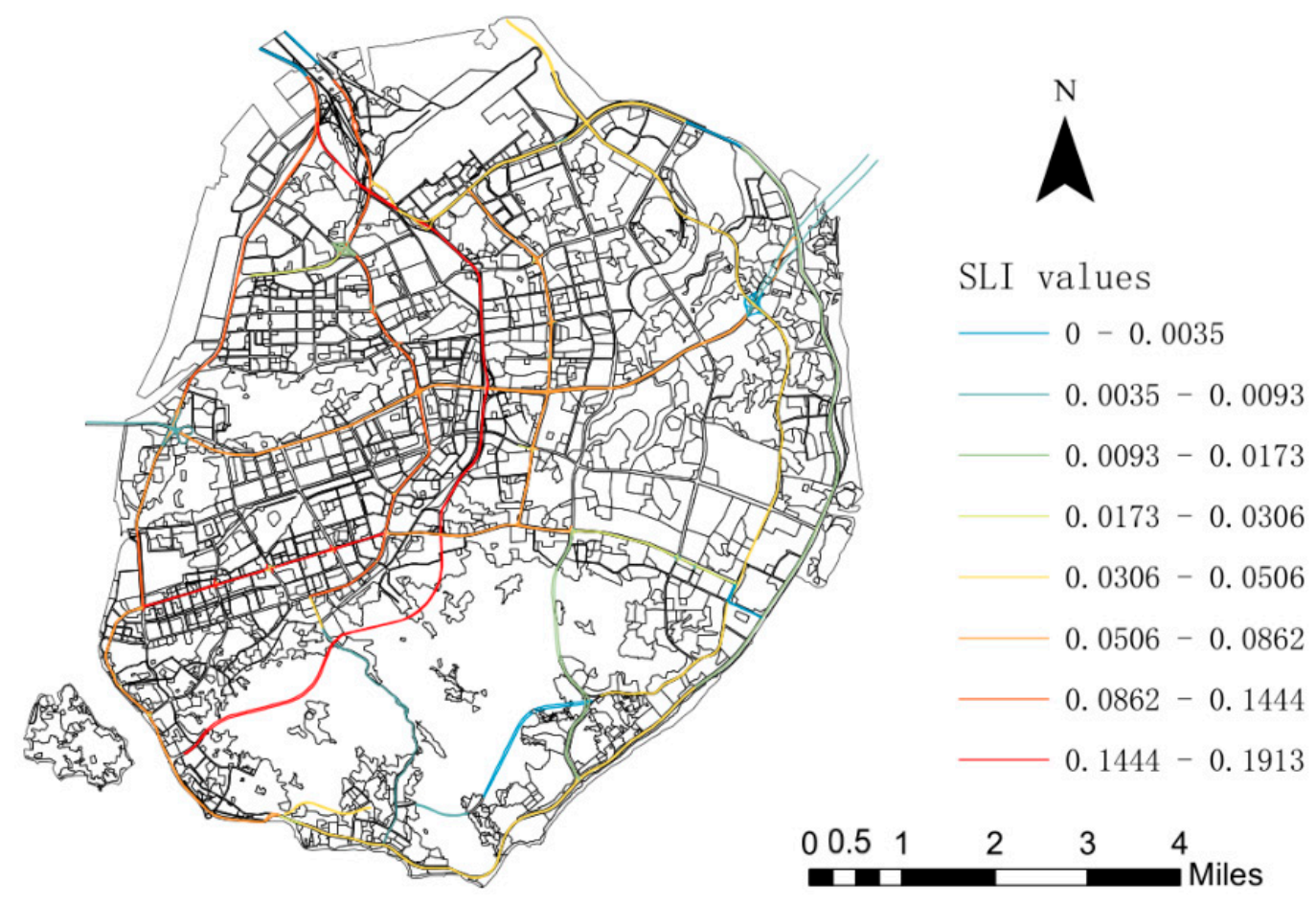

Figure 3. Values of source-sink landscape influence for the arterial roads in Xiamen Island.

The average $S L I$ of the 72 roads investigated in the study was 0.032 . Of all the roads, Chenggong Avenue had the highest SLI (0.191), and 24 roads' SLI values were above the average. The numbers of roads classified as urban expressway, state highways, provincial highways, and county roads that had SLI values above the average for the 72 roads were 1, 4, 5, and 14, respectively. Of the road classifications in the study, the average SLI values for urban expressways, state highways, provincial highways, and county roads were $0.191,0.067,0.030$, and 0.025 , respectively. The urban expressway had the highest influence, followed by state highways, provincial highways, and county roads. We use MATLAB 2014 (MathWorks, Natick, MA, USA) to print the result (Figure 4).

Of the roads that are included in the study, as shown in Figure 5 print by MATLAB 2014 (MathWorks, Natick, MA, USA), traffic carried by the five roads with high SLI values accounts for a small percentage of total traffic. After using ArcGIS to calculate the length of roads, we found that this is because the five outlier roads are relatively short. Although the surrounding "source" and "sink" landscapes have high SLI, the road capacity cannot meet the demand. 

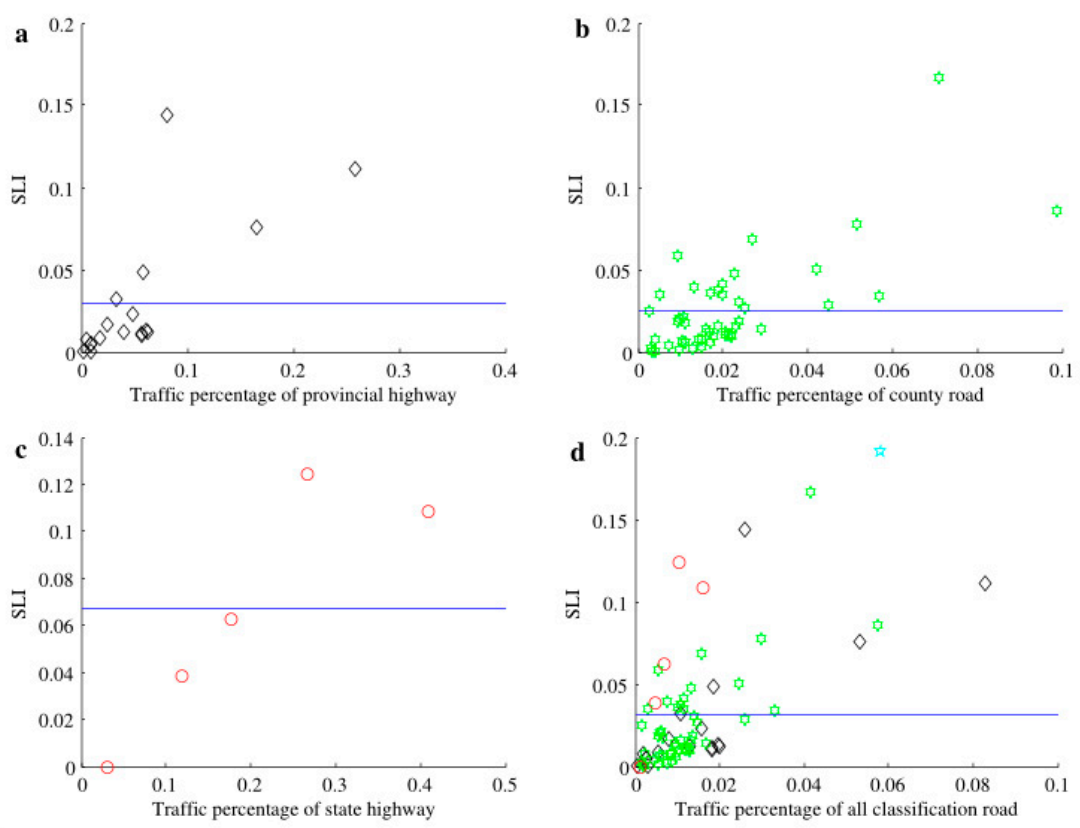

$\diamond$ Provincial highway $\quad$ County road $\bigcirc \quad$ State highway

Traffic percentage of all classification road

Figure 4. (a) Scatter plot of the source-sink landscape influence (SLI) of provincial highways. (b) Scatter plot of the SLI of county roads. (c) Scatter plot of the SLI of state highways. (d) Scatter plot of the SLI of the arterial roads in Xiamen Island.

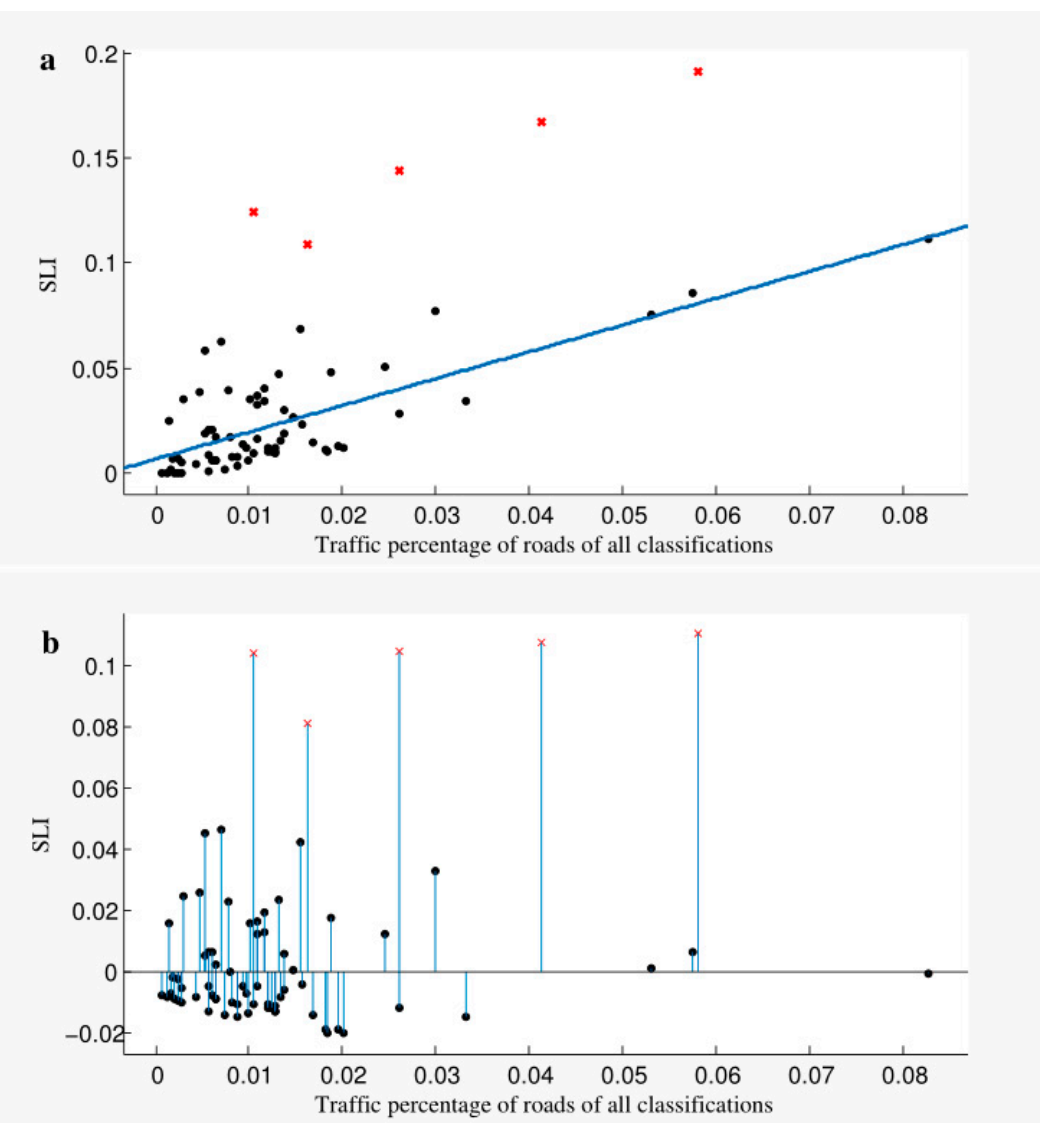

Figure 5. (a) Outlier points shown on scatter plot of the arterial roads in Xiamen Island. (b) Outliers shown on residuals plot of road SLI values. 


\subsection{Correlation Coefficients between SLI and Traffic Flows}

The relationship between the SLI that was obtained from the modified model and the traffic flow in every buffer zone is shown in Table 1 . The correlation coefficient between the SLI of different roads and their traffic flow was 0.684 , indicating a significant direct relationship between these two indices. In contrast, with the same data, the LWLI of the roads was not correlated with their traffic flow, indicating that $L W L I$ is not a good model for representing the relationship between traffic flow and landscape pattern, whether from a single class of roads or all the classifications of roads.

The correlation coefficients between $S L I$ and traffic flow for the state highways, the provincial highways, and the county roads were $0.891,0.731$, and 0.710 , respectively. As Chenggong Avenue was the only urban expressway in Xiamen Island, the correlation coefficient between its SLI and traffic flow could not be calculated. The above results indicate that the landscape types around the state highways were more dependent on the roads themselves and attracted more traffic than the landscape types around other road classifications.

Table 1. Analysis of correlation between SLI or LWLI and traffic flow of different roads.

\begin{tabular}{ccccc}
\hline $\begin{array}{c}\text { Road } \\
\text { Classification }\end{array}$ & $\begin{array}{c}\text { SLI Correlation } \\
\text { Coefficient }\end{array}$ & $\begin{array}{c}\text { Significance } \\
\text { (Two-Tailed Test) }\end{array}$ & $\begin{array}{c}\text { LWLI Correlation } \\
\text { Coefficient }\end{array}$ & $\begin{array}{c}\text { Significance } \\
\text { (Two-Tailed Test) }\end{array}$ \\
\hline County road & $0.710^{* *}$ & 0 & 0.001 & 0.994 \\
Provincial highway & $0.731^{* *}$ & 0.001 & -0.130 & 0.608 \\
State highway & $0.891^{*}$ & 0.0417 & 0.017 & 0.978 \\
Total & $0.684^{* *}$ & 0 & -0.024 & 0.843 \\
\hline
\end{tabular}

Note: the "** and "***" indicate significance at $p$-values of 0.05 and 0.01 , respectively.

\section{Discussion}

As shown in Section 4, different road types tend to have different SLI values, and SLI is correlated with traffic flow. In order to explore the reasons for these findings, we chose targeted analysis methods for further analysis. Although the coefficient of correlation between the SLI value and the traffic flow could not be calculated for the only urban expressway, the influence of its source-sink landscapes on traffic flow should be the greatest of all the roads in the study because it had the highest SLI value (Figure 3). The results shown in Figure 4 and Table 1 indicated that both the SLI values of the state highways and the correlation between SLI and traffic flow were higher than those of the provincial highways and the county roads, which means that the state highways had more influence on the surrounding landscape pattern than did the provincial highways and county roads. The detailed causes for this were analyzed using Patch Analyst (Centre for Northern Forest Ecosystem Research, Thunder Bay, ON, Canada) in ArcGIS along with SPSS 16 software (IBM Corporation, Endicott, NY, USA). Because of the variation in the surrounding areas and the numbers of different roads within each classification, as well as in the landscape pattern characteristics, different landscape indices were chosen to represent different aspects of the landscape pattern characteristics [34]. On the level of patch type, the core area (CA), the area weighted average shape factor (AWMSI), and the mean patch size (MPS) were used. On the level of landscape, Shannon's diversity index (SHDI) was used.

\subsection{Influence of Core Area on Traffic Flow}

At first, the contribution of the core area of each source-sink landscape determined its attraction for traffic flow. The greater the contribution of the core area, the heavier the traffic flow on the roads. The CA of the different land usage types in different roads' buffer zones was calculated and analyzed using Patch Analyst (Centre for Northern Forest Ecosystem Research, Thunder Bay, ON, Canada) and SPSS 16 software (IBM Corporation, Endicott, NY, USA). Correlations between traffic flow and core area for urban residential lands, residential lands in urban villages, industrial and mining lands, commercial and service lands, and mixed commercial and residential lands were significantly positive, 
but the correlations between traffic flow and core area for construction sites and educational lands were not significant (Table 2).

Table 2. Correlation coefficients between core area and traffic flow.

\begin{tabular}{cc}
\hline Land Usage Type & Correlation Coefficient \\
\hline Urban residential land & 0.739 \\
Residential land in urban village & 0.480 \\
Educational land & 0.117 \\
Industrial and mining land & 0.582 \\
Construction site & -0.001 \\
Commercial and service land & 0.541 \\
Mixed commercial and residential land & 0.516 \\
\hline
\end{tabular}

The contribution of the core area was calculated by multiplying the ratio of the core area of a land usage type in the source-sink landscape by the corresponding weight. The result showed that the source of the weight $\left(w_{j}\right.$ in 3.3.2) was 0.115 and the sink of the weight was 0.885 for the urban expressway, the average sources of the weight was 0.068 and the average sinks of the weight was 0.349 for the state highways, 0.026 and 0.183 for the provincial highways, 0.015 and 0.146 for the county roads. For all of the land usage types except for industrial and mining lands, the contribution of the core area was highest for the urban expressway, followed by state highways, provincial highways, and county roads (Table 3 ).

Table 3. Contribution of core area.

\begin{tabular}{|c|c|c|c|c|}
\hline Land Usage Type & $\begin{array}{c}\text { Road } \\
\text { Classification }\end{array}$ & $\begin{array}{l}\text { Core Area } \\
\qquad\left(\mathrm{m}^{2}\right)\end{array}$ & $\begin{array}{l}\text { Percentage of } \\
\text { Core Area (\%) }\end{array}$ & $\begin{array}{l}\text { Contribution } \\
\text { of Core Area }\end{array}$ \\
\hline \multirow{4}{*}{ Urban residential land } & Urban expressway & 673.2219 & 0.5067 & 0.0583 \\
\hline & State highway & 519.6150 & 0.4078 & 0.0276 \\
\hline & Provincial highway & 3239.9974 & 0.4149 & 0.0110 \\
\hline & County road & 5385.2851 & 0.3561 & 0.0053 \\
\hline \multirow{4}{*}{ Urban village land } & Urban expressway & 115.2985 & 0.0868 & 0.0100 \\
\hline & State highway & 114.5621 & 0.0899 & 0.0061 \\
\hline & Provincial highway & 890.3992 & 0.1140 & 0.0030 \\
\hline & County road & 2155.4179 & 0.1425 & 0.0021 \\
\hline \multirow{4}{*}{ Industrial and mining land } & Urban expressway & 286.9834 & 0.2160 & 0.1912 \\
\hline & State highway & 86.8192 & 0.0681 & 0.0238 \\
\hline & Provincial highway & 932.5871 & 0.1194 & 0.0219 \\
\hline & County road & 2500.7271 & 0.1654 & 0.0242 \\
\hline \multirow{4}{*}{ Commercial and service land } & Urban expressway & 143.6290 & 0.1081 & 0.0957 \\
\hline & State highway & 99.0594 & 0.0777 & 0.0271 \\
\hline & Provincial highway & 824.2738 & 0.1056 & 0.0193 \\
\hline & County road & 1315.4769 & 0.0870 & 0.0127 \\
\hline \multirow{4}{*}{$\begin{array}{l}\text { Mixed commercial and } \\
\text { residential land }\end{array}$} & Urban expressway & 41.1475 & 0.0310 & 0.0036 \\
\hline & State highway & 60.2074 & 0.0472 & 0.0032 \\
\hline & Provincial highway & 342.7641 & 0.0439 & 0.0012 \\
\hline & County road & 360.0863 & 0.0238 & 0.0004 \\
\hline
\end{tabular}

\subsection{Influence of Landscape Diversity on Traffic Flow}

We next performed a landscape-scale analysis. The Shannon's diversity indices (SHDI) around the different roads were analyzed using Patch Analyst (Centre for Northern Forest Ecosystem Research, Thunder Bay, ON, Canada) in ArcGIS software (ESRI, Redlands, CA, USA). In an area, the more abundant the land usage, the higher the fragmentation degree, the greater the information content 
of the uncertainty, and the higher the calculated SHDI values [35]. The SHDI was highest in the landscapes surrounding county roads (1.717), followed by those surrounding provincial highways (1.663), state highways (1.598), and the urban expressway (1.388). The landscapes surrounding the urban expressway had the lowest fragmentation degree of all the roads in the study, reflecting the concentrated distribution of land usage types around the urban expressway. This concentrated distribution likely gave rise to concentrated traffic flow, whereas fragmented landscapes would instead cause dispersion of the traffic flow. This resulted in the urban expressway having the highest SLI value, and in the state highways showing high correlation between source-sink landscape patterns and traffic flow.

\subsection{Influence of Flow Landscape Patterns on Traffic Flow}

AWMSI is an important index that is used to measure the spatial pattern complexity of landscapes, a characteristic that influences many ecological processes. AWMSI $=1$ when all of the patches are square and increases as the shape complexity of patches increases. MPS is used to measure the interior heterogeneity of landscapes. Smaller MPS values represent a higher degree of fragmentation [36]. Some studies have shown that AWMSI and MPS are associated with road connectivity $[37,38]$. Thus, AWMSI and MPS were used for the analysis of the flow landscape patterns. The urban expressway has the largest AWMSI and MPS values of all the roads in the study, followed by the state highways, the provincial highways, and the county roads. The result was print by MATLAB 2014 (Figure 6). This result indicates that the landscapes surrounding the state highways and the urban expressway have more complex shapes and are less fragmented than those that are surrounding the other two types of roads, and that the flow landscapes of the urban expressway are not only complex in shape but also more concentrated. This kind of shape means that the traffic flow is more concentrated in a certain period of time and the $S L I$ value is higher.

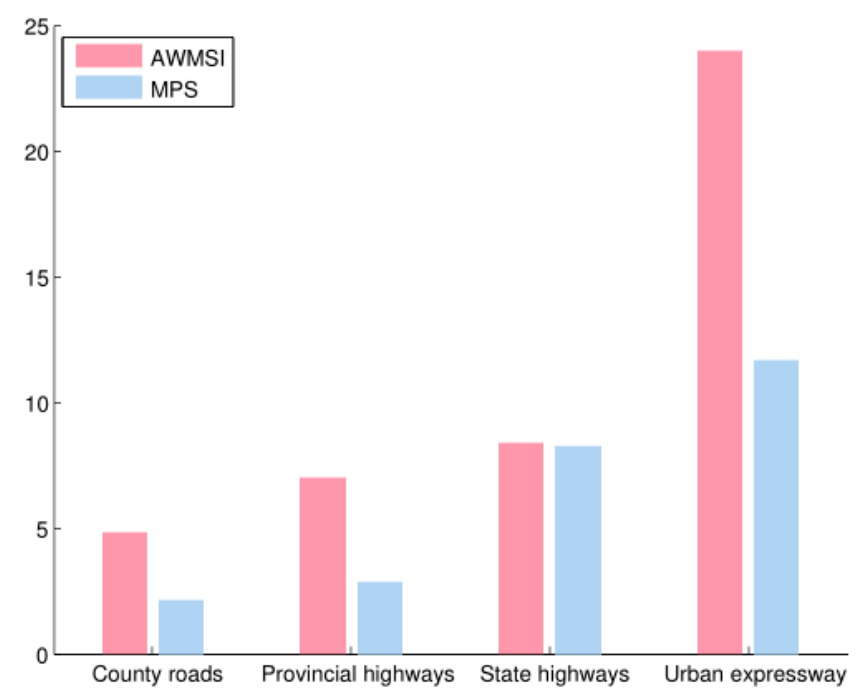

Figure 6. Area weighted average shape factor (AWMSI) and mean patch size (MPS) values of different roads.

\subsection{The Purpose of the SLI Value}

Urban development almost inevitably leads to increased vehicle traffic on roads [39]. In many regions, as the urban population increases and the number of vehicles increases, the cost of urban traffic congestion is increasing [40]. It is necessary to make plans to reduce traffic congestion in planning new developments or renovating old cities. When planning an area, it is difficult to determine the relationship between landscape pattern and the traffic flow with a unified standard using traditional methods. In contrast to the various traditional landscape indices, which each only explain a part of 
the meaning in an ecological system, SLI is a comprehensive index. The application of source-sink landscape pattern theory can not only eliminate landscape types that have little or no effect on the ecological process under study, such as woodland, farmland, and bare land in the context of a commuter traffic study, but also integrate different factors, such as relative distance, landscape area, and numbers of POI, to produce a single value useful in evaluating landscape patterns. This method can reveal different aspects of the relationship between the landscape patterns around roads and the commuter traffic flow on those roads. As $S L I$ value is a comprehensive indicator, by calculating the $S L I$ value, researchers can elucidate the source-sink landscape influence in a particular region. SLI values can be used in all the stages of planning. Before formal planning begins, it could be used for forecasting, during the planning stage it could be used for adjustment, and after plans are completed it could be used for inspection of the results. A single $S L I$ value is not of practical use, and a comparison with other SLI values is needed.

In this study, the $S L I$ average of the regions in the top ten for highest $S L I$ values was 0.0967, 18.18 times the mean of the lowest ten regions (0.0053). This indicates that when the SLI value of a planned development is much higher than that of a mature area with good road conditions, planners may need to adjust the distribution of roads or the distribution of source and sink landscapes in the planning area. In order to improve the transportation efficiency of urban transport corridors, the superposition of different traffic flows in the same road space should be reduced [41], and planners should give adequate consideration to the coordinated development of urban land use and transportation.

\section{Conclusions}

(1) Source-sink landscape theory can be applied to the behavior processes of urban commuter traffic. However, the processes that are involved in commuter traffic are more consistent with an additive model than with the Location-Weighted Landscape Index ( $L W L I)$, unlike the process of accumulation of nonpoint source pollutants in natural landscapes, which can be measured by the LWLI. An additive model can better represent the relationship between the source-sink landscape pattern and commuter traffic flow.

(2) Different roads have different SLI values, and higher values of SLI indicate that the source-sink landscape had greater influence on traffic flow on that road. The correlation coefficient can be used to confirm these results. In this study, the SLI values of the arterial roads in Xiamen Island are highest for the urban expressway, followed by the state highways, the provincial highways, and the county roads. This indicates that the source-sink landscape patterns that are surrounding the urban expressway are most attractive to traffic flow. Commuting vehicles are more dependent on the urban expressway than on any other road.

(3) Through correlation analysis, researchers can verify that there is a relationship between SLI values and traffic flows in different areas. This method allows for researchers to perform detailed analyses; for example, traditional landscape pattern indexes can be employed to find the reasons for differences in SLI values or to identify the factors that cause differences in the correlation coefficients between $S L I$ and traffic flows. Source-sink landscape theory can contribute new ideas for the study of the relationships between urban landscape patterns and traffic.

(4) This method is not designed for any specific road type; it is a method for evaluating the influence of the landscapes surrounding any road. A single $S L I$ value is not of practical use; it must be used for comparison with different regions or time points. For example, planners can calculate and compare the $S L I$ values in a newly developing district and in a completed area to predict commuting times, in order to determine whether there might be congestion in the new district, and to further aid in landscape planning.

At present, the SLI model is in a preliminary stage of development. Additional case studies are required to further enrich the model and its applications. 
Acknowledgments: This study was supported by National Natural Science Foundation of China, Grant No. 41501196 and No. 41471137. The author is grateful to the reviewers and the editor for their help.

Author Contributions: Quanyi Qiu provided the idea and made valuable suggestions on the writing and revision of the paper. Lina Tang, Huaxiang Chen and Ziyan Wang mainly contributed to put forward opinions on the structure of this paper. All authors have read and approved this manuscript.

Conflicts of Interest: The authors declare no conflict of interest.

\section{References}

1. Pulliam, H.R. Sources, sinks, and population regulation. Am. Nat. 1988, 132, 652-661. [CrossRef]

2. Hansen, A.; Liu, J.; Hill, V.; Morzillo, A.T.; Wiens, J.A. Contribution of source-sink theory to protected area science. In Sources Sinks \& Sustainability; Cambridge University Press: Cambridge, UK, 2011; pp. 339-360.

3. Ludford, A.; Cole, V.J.; Porri, F.; Mcquaid, C.D.; Nakin, M.D.V.; Erlandsson, J. Testing source-sink theory: The spill-over of mussel recruits beyond marine protected areas. Landsc. Ecol. 2012, 27, 859-868. [CrossRef]

4. Chen, L.; Fu, B.; Zhao, W. Source-sink landscape theory and its ecological significance. Front Acta Ecol. Sin. 2006, 26, 1444-1449. [CrossRef]

5. Chen, L.; Fu, B.; Xu, J.; Gong, J. Location-weighted landscape contrast index: A scale independent approach for landscape pattern evaluation based on source-sink ecological processes. Acta Ecol. Sin. 2003, 23, 2406-2413. [CrossRef]

6. Chen, L. Source-Sink Landscape Pattern Analysis and Its Applications, 1st ed.; China Science Publishing \& Media Ltd.: Beijing, China, 2016; pp. 15-25, ISBN 9787030467621.

7. Basnyat, P.; Teeter, L.D.; Flynn, K.M.; Lockaby, B.G. Relationships between Landscape Characteristics and Nonpoint Source Pollution Inputs to Coastal Estuaries. Environ. Manag. 1999, 23, 539-549. [CrossRef]

8. Gustafson, E.J. Quantifying landscape spatial pattern: What is the state of the art? Ecosystems 1998, 1, 143-156. [CrossRef]

9. Wu, J. Paradigm shift in ecology: An overview. Acta Ecol. Sin. 1996, 5, 449-459. [CrossRef]

10. Lv, Y.; Chen, L.; Fu, B. Analysis of the integrating approach on landscape pattern and ecological processes. Prog. Geogr. 2007, 26, 1-10. [CrossRef]

11. Jing, Y.; Zhang, S.; Li, Y. Landscape pattern and SHDI spatial structure characteristics of rural urban fringe: A case study in Jingyue development zone in Changchun city. Resour. Sci. 2007, 29, 43-49. [CrossRef]

12. Chen, A.; Zhao, X.; Yao, L.; Chen, L. Application of a new integrated landscape index to predict potential urban heat islands. Ecol. Indic. 2016, 69, 828-835. [CrossRef]

13. Sun, R.; Chen, L.; Wang, W.; Wang, Z. Correlating landscape pattern with total nitrogen concentration using a location-weighted sink-source landscape index in the Haihe river basin, China. Environ. Sci. 2012, 33, 1784-1788. [CrossRef]

14. Li, H.; Wei, W.; Chen, J.; Li, X.; Zhang, B. Research on soil erosion based on location-weighted landscape index (LWLI) in Guanchuanhe river basin, Dingxi, Gansu province. Acta Ecol. Sin. 2013, 33, 4460-4467. [CrossRef]

15. Jiang, M.; Chen, H.; Chen, Q. A method to analyze "source-sink" structure of non-point source pollution based on remote sensing technology. Environ. Pollut. 2013, 182, 135-140. [CrossRef] [PubMed]

16. Li, Y. A study on the relationship between urban transportation system and urban land use structure. Trop. Geogr. 1998, 18, 307-310. [CrossRef]

17. Zhou, J.; Xiao, R.; Sun, X. Relationships between settlement morphology transition and residents commuting energy consumption. Chin. J. Appl. Ecol. 2013, 24, 1977-1984. [CrossRef]

18. Mao, J.; Yan, X. Study on mutual mechanism between urban transport system and urban space pattern: A case study of Guangzhou. City Plan. Rev. 2005, 29, 45-49. [CrossRef]

19. Huang, N.; Lin, T.; Zhang, W.; Cao, Y. Gradient analysis and comparison of landscape pattern along different expansion axes of Tong'an district in Xiamen city. Prog. Geogr. 2009, 28, 767-774.

20. Chen, T. Commuters Travel Behavior Characteristics and Analysis Method. Ph.D. Thesis, Beijing Jiaotong University, Beijing, China, 2007.

21. Wang, J.; Lin, T.; Zhang, G. Spatiotemporal simulation of urban settlement morphology: A case study of Xiamen Island. Acta Ecol. Sin. 2017, 37, 2954-2969. [CrossRef] 
22. Ding, M. Build harmonious development of bay city's integrative transportation system—Xiamen's urban transportation development strategy planning. Fujian Archit. Constr. 2008, 122, 96, 115-117.

23. Zhao, C.; Feng, S. Exploration about urban traffic patterns based on the multi-center spatial structure-Illustrated by the case of Xiamen. J. Qingdao Univ. Technol. 2016, 37, 53-59, 90. [CrossRef]

24. Edwards, P.; Barra, T.D.L. Integrated land use and transport modelling: Decision chains and hierarchies. J. R. Stat. Soc. 1989, 42, 191. [CrossRef]

25. De la Barra, T.; Perez, B.; Vera, N. TRANUS-J: Putting large models into small computers. Environ. Plan. B Plan. Des. 1984, 11, 87-101. [CrossRef]

26. Zhou, J.; Lin, J.; Cui, S.; Qiu, Q.; Zhao, Q. Exploring the relationship between urban transportation energy; consumption and transition of settlement morphology: A case study on Xiamen Island, China. Habitat Int. 2013, 37, 70-79. [CrossRef]

27. Qiu, Q. Simulation of Residential Commuting Travel and Evaluation of Carbon Emission under Transformation of Urban Settlement Morphology. Ph.D. Thesis, Graduate University of Chinese Academy of Sciences, Beijing, China, 2011.

28. Zhang, Y.; Feng, X.; Du, J.; Gu, G. Study on extraction of urban green space from IKONOS remote sensing images. Geogr. Res. 2004, 23, 274-280. [CrossRef]

29. Xie, J.; Li, Y. The extraction of building distribution information of different heights in a city from the shadows in a IKONOS image. Remote Sens. Land Resour. 2004, 16, 4-6. [CrossRef]

30. Shu, S.; Yang, M. Hyperspectral image classification method based on watershed segmentation and sparse representation. Comput. Sci. 2016, 43, 89-94. [CrossRef]

31. Modelistica. TRANUS: Integrated Land Use and Transport Modeling System; Modelistica Company: Caracas, Venezuela; Mexico, 2007.

32. Chen, L.; Tian, H.; Fu, B.; Zhao, X. Development of a new index for integrating landscape patterns with ecological processes at watershed scale. Chin. Geogr. Sci. 2009, 19, 37-45. [CrossRef]

33. Dai, Q.; Liu, G.; Jiang, X.; Liu, M.; Wang, Y. An evaluation on sustainable development of eco-economic system in small watershed in hilly area of northeast China. Acta Geogr. Sin. 2005, 60, 209-218.

34. Huang, N.; Lin, T.; Chen, X. Analysis and comparison of landscape patterns in the surroundings of different traffic lines-Xiamen Island as an example. Yunnan Geogr. Environ. Res. 2009, 21, 42-46, 51. [CrossRef]

35. Yang, Y. Urban fringe extraction and its change monitoring using multi-temporal tm image. Remote Sens. Inf. 2009, 3, 49-53. [CrossRef]

36. Huang, S.; Chen, Y.; Zhang, R.; Wu, W.; Wei, C. Spatial correlation analysis of land fragmentation and agriculture development based on landscape indexes. Agric. Res. Arid Areas 2015, 3, 238-244. [CrossRef]

37. Li, H.; Li, S.; Lv, T.; Liu, C. Evaluation of farmland fragmentation due to the impact of land consolidation based on the view of landscape pattern. Resour. Environ. Yangtze Basin 2017, 26, 67-73. [CrossRef]

38. Yang, S. Effect of Road on Landscape Structure in Shenzhen City. Master's Thesis, Beijing University, Beijing, China, 2012.

39. Zupanovic, D.; Grgurevic, I.; Filipcic, T. Importance of collecting and analyzing data on traffic flow load in urban environments. In Proceedings of the 30th International Conference on Information Technology Interfaces, Dubrovnik, Croatia, 23-26 June 2008; pp. 809-814. [CrossRef]

40. Oh, S.D.; Kim, Y.J.; Hong, J.S. Urban traffic flow prediction system using a multifactor pattern recognition model. IEEE Trans. Intell. Transp. Syst. 2015, 16, 2744-2755. [CrossRef]

41. Liang, H. Diverging traffic flows and design patterns for urban corridors. Urban Transp. China 2009, 7, 78-84. [CrossRef]

(C) 2017 by the authors. Licensee MDPI, Basel, Switzerland. This article is an open access article distributed under the terms and conditions of the Creative Commons Attribution (CC BY) license (http:/ / creativecommons.org/licenses/by/4.0/). 